\title{
A influência de microfibras de celulose no estado fresco de argamassas
}

The influence of cellulose microfibers in on the fresh state of mortars

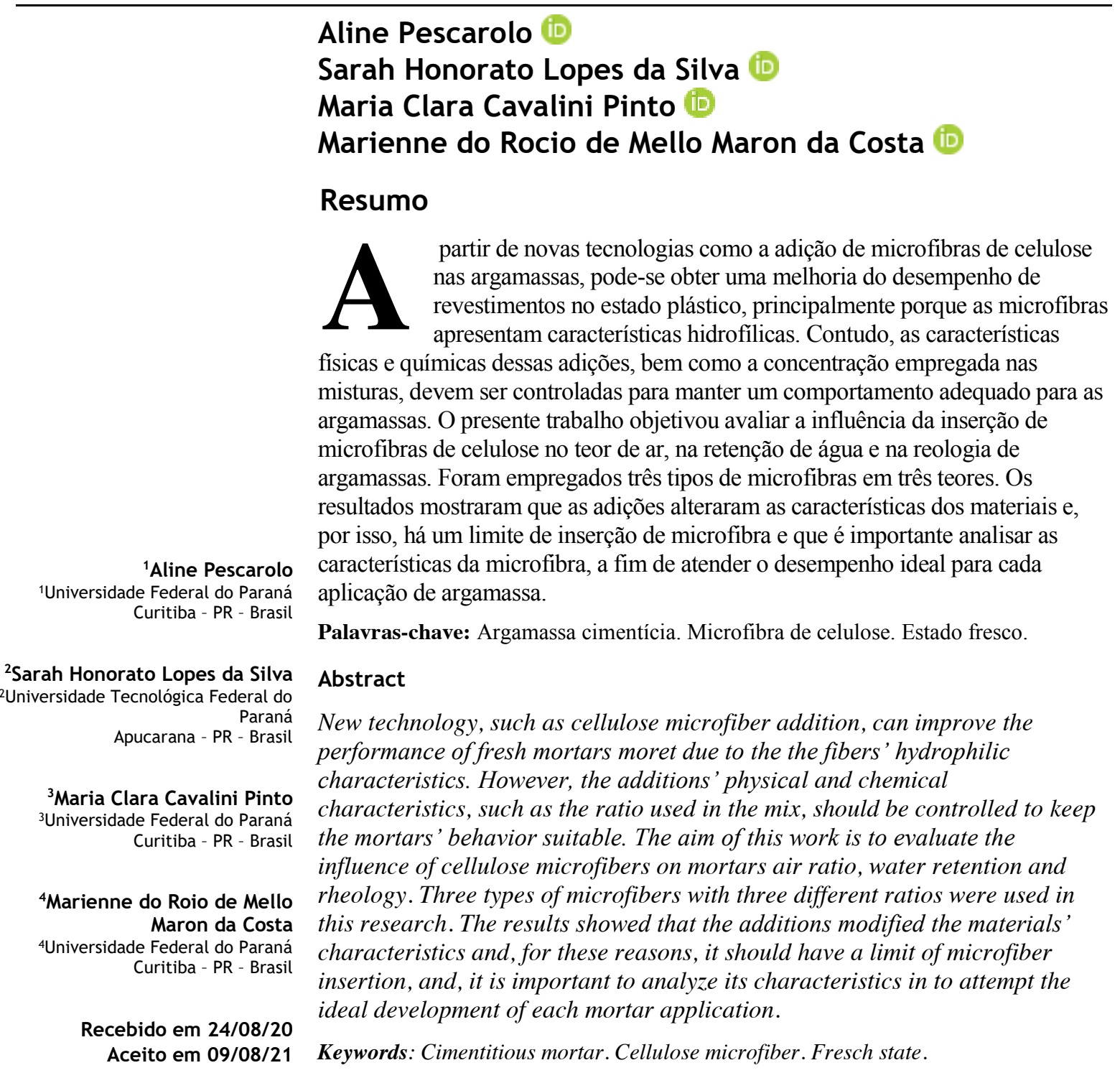

PESCAROLO, A.; SILVA, S. H. L. da.; PINTO, M. C. C.; COSTA, M. do R. de M. M. da. A influência de microfibras de 179 celulose no estado fresco de argamassas. Ambiente Construído, Porto Alegre, v. 22, n. 1, p. 179-190, jan./mar. 2022. ISSN 1678-8621 Associação Nacional de Tecnologia do Ambiente Construído. http://dx.doi.org/10.1590/s1678-86212022000100586 


\section{Introdução}

Para seu melhor desempenho no estado fresco, as argamassas de revestimento devem apresentar coesão, trabalhabilidade, poder de retenção de água e de ar incorporado. Estas características refletem no estado endurecido por meio da capacidade de aderência ao substrato, resistência mecânica, moderada retração por secagem e módulos de deformação menores.

O desempenho dos revestimentos argamassados pode ser influenciado pelas suas características reológicas e mecânicas, devendo responder da melhor forma às solicitações impostas pelo meio. Desta forma, os revestimentos aplicados nas edificações devem ser projetados para suportar as diversas demandas, pois estão entre os elementos mais suscetíveis à ação do meio ambiente.

Para que estas necessidades sejam atendidas, o uso de fibras de origem vegetal na argamassa pode oferecer algumas vantagens, além da possibilidade de reaproveitamento de resíduos de subprodutos de outras atividades econômicas. Este seria o caso das fibras de celulose, que tendem a proporcionar maior resistência ao impacto, promovendo a absorção de energia, a possibilidade de trabalho pós-físsurado e um aumento da capacidade de isolamento termoacústico, favorecendo a redução do módulo de elasticidade e elevando a resistência à tração (JAWAID; KHALIL, 2011; ARDANUY; CLARAMUNT; TOLEDO FILHO, 2015).

\section{Referencial teórico}

Os compósitos cimentícios reforçados com fibras de celulose são complexos e podem apesentar problemas de má distribuição, gerando vazios e aumentando a porosidade do material. Desta forma, a ordem da mistura e a padronização dos procedimentos é de substancial importância para que se obtenha o desempenho esperado (SAVASTANO JUNIOR, 2000).

Ressalta-se ainda que o emprego de fibras celulósicas normalmente proporciona um aumento da resistência mecânica em matrizes cimentícias em virtude das mudanças microestruturais na matriz, que são consequência da contínua hidratação dos grãos de cimento que cercam a fibra. Isso ocorre porque a zona de transição interfacial se torna mais densa devido à reprecipitação dos produtos de hidratação do cimento nas camadas porosas (SANTOS; TEIXEIRA; SAVASTANO JUNIOR, 2017).

No tocante à durabilidade dos componentes da fibra em misturas cimentícias, a celulose tem maior resistência à deterioração em relação aos demais elementos em função de sua alta cristalinidade. Assim, quanto mais celulose pura a fibra apresentar em sua composição química, maior será sua resistência a meios alcalinos. Quanto à estrutura física, as fibras celulósicas são compostas por um aglomerado de células formadas por microfibrilas que se unem pelas lamelas intercelulares. A fração de celulose corresponde a essas microfibrilas, e a fibra - ou macrofibra - é o conjunto formado pela união desses filamentos de celulose com a lignina e a hemicelulose (MENDES et al., 2015; WEI; MEYER, 2015).

As fibras naturais são substancialmente hidrofílicas em razão da presença da celulose e do grupo hidroxila em suas paredes celulares (ONUAGULUCHI; BANTHIA, 2016). Em vista disso, outros autores constataram que o alto teor do grupo hidroxila na celulose aumenta as propriedades de absorção de umidade das fibras à base de plantas. Portanto, as fibras celulósicas atuam diferentemente das fibras sintéticas quando adicionadas à matriz cimentícia (SILVA, 2006; GURGEL, 2007; FARUK et al., 2012). Assim, na Figura 1, mostra-se a representação da fibra de celulose.

A ligação entre a fibra de celulose e o cimento Portland desempenha um papel importante na transferência de cargas dentro da matriz. Essa ligação pode ser de natureza física (intertravamento mecânico) ou de natureza química (principalmente ligações de hidrogênio com as moléculas de $\mathrm{H}_{2} \mathrm{O}$ da água de amassamento) ou uma combinação de ambas (NARAGANTI; PANNEM; PUTTA, 2019). Além disso, as fibras vegetais apresentam significativo volume de vazios, de modo que têm relevante capacidade de absorção de água, o que resulta em materiais sensíveis a pequenas variações de umidade. A absorção de água das fibras é função tanto do seu arranjo físico como das características microestruturais de seus componentes químicos individualmente (SALES, 2006; MOTTA; SOUZA; SILVA, 2021).

As fibras em geral podem apresentar dimensões - comprimento e espessura - diferentes em escala nano e macrométrica. As fibras longas e médias (comprimento maior que $400 \mu \mathrm{m}$ ), geralmente têm maior capacidade de entrelaçamento entre si, o que aumenta sua capacidade de distribuição das tensões no interior do material (PERUZZI, 2002). Por outro lado, as fibras curtas (comprimento médio de $50 \mu \mathrm{m}$ ) tendem a se dispersar de uma forma mais homogênea, o que auxilia na retenção da água de amassamento dentro da mistura (SIQUEIRA, 2006). 
Figura 1 - Representação esquemática das fibras de celulose

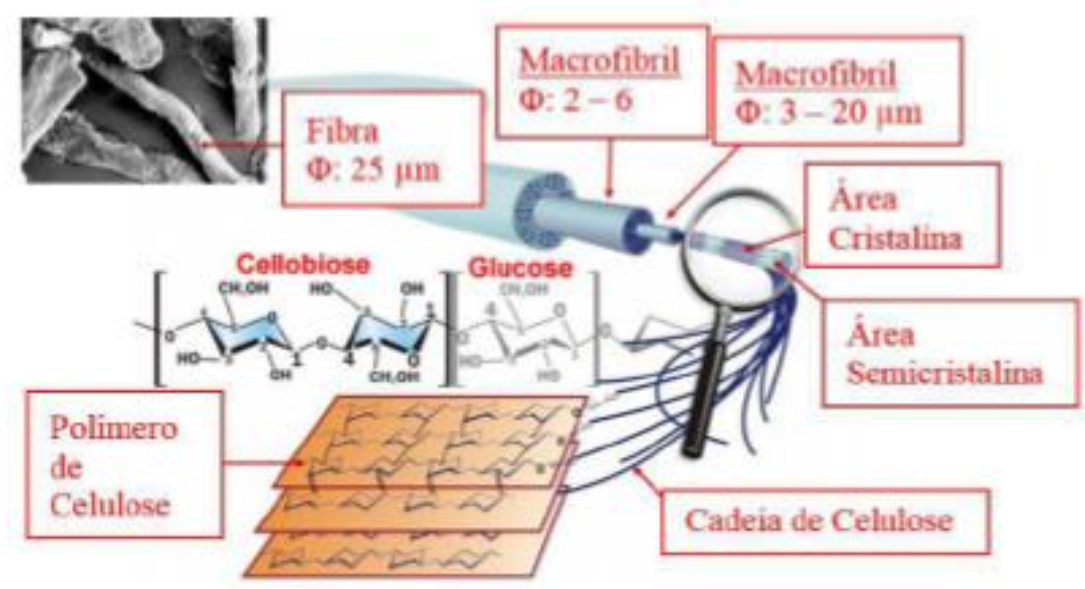

Fonte: adaptado de J. Rettenmaier \& Söhne (2012).

Este trabalho visa avaliar a influência de três fibras de celulose de diferentes dimensões e características, físicas e químicas, no comportamento de argamassas cimentícias no estado fresco.

\section{Materiais e métodos}

\section{Materiais}

O aglomerante empregado na formulação das argamassas foi o cimento do tipo CPIII 40-RS, por ter como característica principal alto teor de adição de escória de alto forno, apresentando reação de hidratação mais lenta e gerando menor calor de hidratação na mistura. Sendo assim, partiu-se da premissa que a ação da fibra não seria prejudicada pela reatividade do cimento. Como aditivo, optou-se pelo retentor de água MHS 10012 P6 com nível de viscosidade de $1000 \mathrm{mPa} \cdot \mathrm{s}$ com o intuito de diminuir o consumo de água da mistura. Os agregados utilizados foram fíler calcário e areia proveniente de cava de granulometria média. Na Figura 2 é possível verificar a distribuição granulométrica da areia empregada na pesquisa, em concordância com a NBR NM 248 (ABNT, 2003).

Para realizar este estudo também foram empregadas microfibras de celulose de três diferentes comprimentos: longo, médio e curto. Estas são provenientes de eucalipto e compostas de alfa-celulose, betacelulose, lignina e extratos etéreos. A Tabela 1, a seguir, apresenta as características das microfibras.

As microfibras apresentam capacidade de armazenar água em seu interior, por meio de seus microtubos, conforme apresentado na Figura 3.

Na Figura 4 é possível observar o aspecto das microfibras de celulose.

\section{Mistura}

A relação água/cimento $(\mathrm{a} / \mathrm{c})$ adotada para a formulação de referência foi de 1,34 . Partindo da quantidade de água da argamassa de referência, optou-se por adicionar à mistura uma massa de água igual à massa das microfibras empregadas no traço. O traço em massa da argamassa anidra apresentou proporções de $75,3 \%$ de areia, $14 \%$ de cimento, $10 \%$ de fíler calcário, $0,02 \%$ de aditivo modificador de viscosidade e três diferentes teores de microfibras - 0,5\%, $0,3 \%$ e $0,1 \%$ - da massa dos materiais secos, conforme indicação do fabricante. Na Tabela 2 é possível verificar as 10 formulações desenvolvidas no trabalho, incluindo a argamassa de referência.

Adotou-se como procedimento de mistura o indicado pela norma NBR 16541 (ABNT, 2016a). Primeiramente os materiais secos foram homogeneizados em sacos plásticos. A seguir, foram depositados na argamassadeira de eixo vertical e novamente misturados na velocidade lenta durante 1 minuto. Ainda com a argamassadeira ligada, adicionou-se a água durante 30 segundos. Em seguida, desligou-se o equipamento para a raspagem da cuba e homogeneização manual com espátula. Por fim, misturou-se novamente a argamassa em velocidade lenta durante mais 30 segundos. Esse procedimento foi adotado para garantir a adequada dispersão das microfibras de celulose. 
Figura 2 - Curva granulométrica da areia

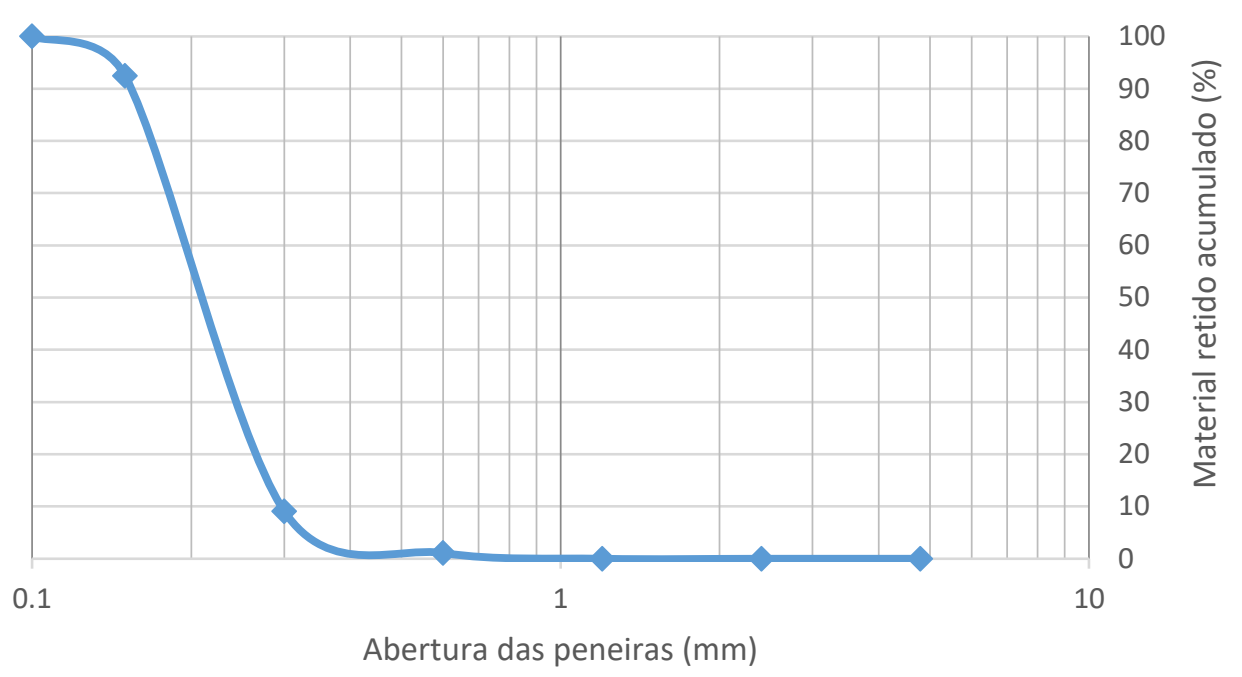

Tabela 1 - Caracterização das microfibras empregadas

\begin{tabular}{c|c|c|c|c}
\hline Microfibras & Comprimento $(\boldsymbol{\mu} \mathbf{m})$ & Diâmetro $(\boldsymbol{\mu} \mathbf{m})$ & Teor de celulose $(\%)$ & Densidade $\left(\mathbf{g} / \mathbf{c m}^{\mathbf{3}}\right)$ \\
\hline Longa & 500 & 35 & 90 & $70-100$ \\
Média & 400 & 45 & 80 & $75-105$ \\
Curta & 45 & 25 & 99,5 & $220-280$ \\
\hline
\end{tabular}

Fonte: fornecida pelo fabricante.

Figura 3 - Ilustração da microfibra empregada na mistura

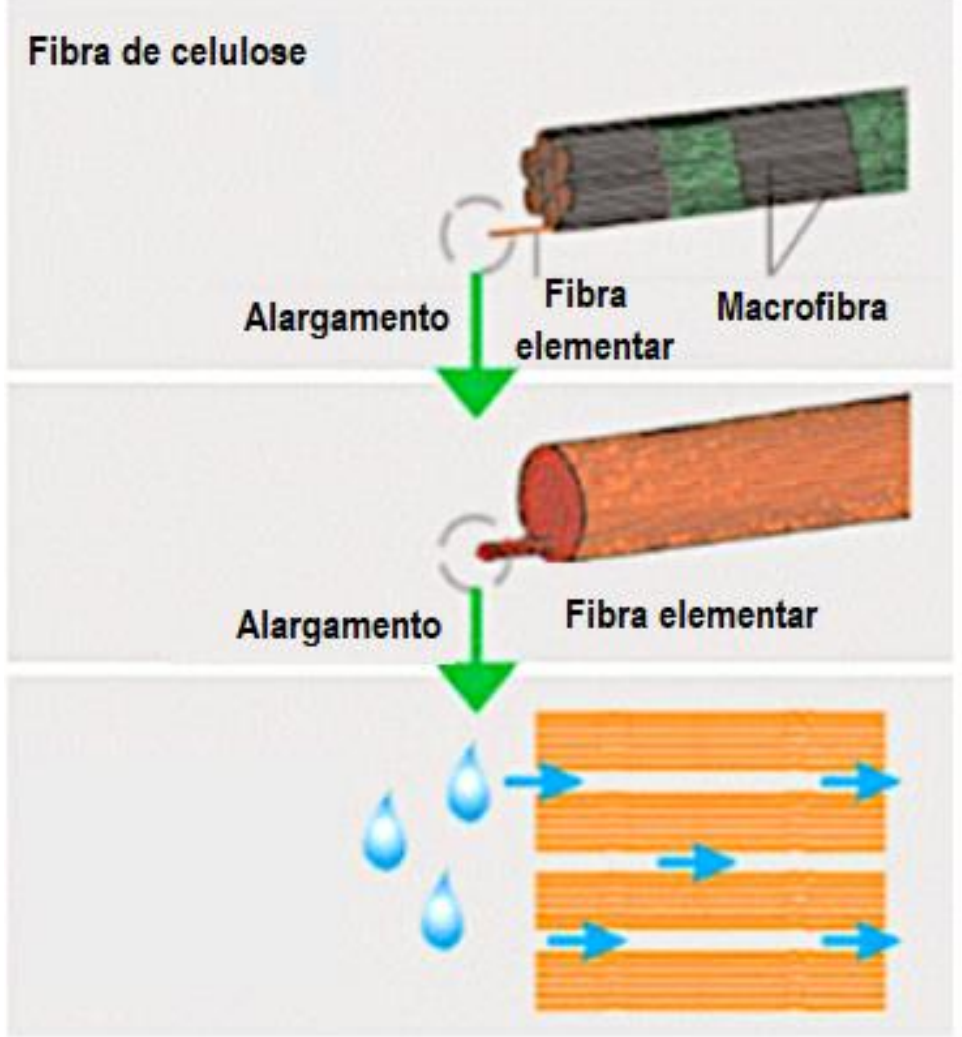

Fonte: adaptado de J. Rettenmaier \& Söhne (2012).

182 Pescarolo, A.; Silva, S. H. L. da.; Pinto, M. C. C.; Costa, M. do R. de M. M. da 
Figura 4 - Microfibras de celulose
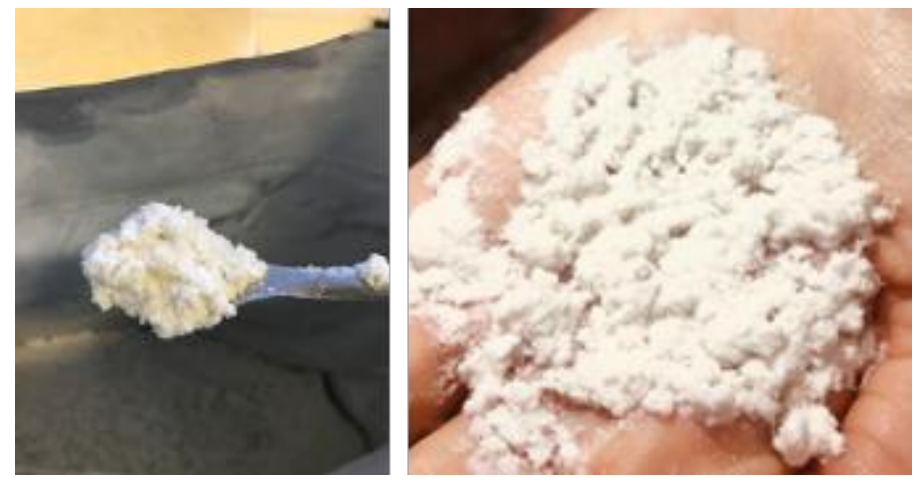

Tabela 2 - Formulações das argamassas

\begin{tabular}{c|c|c|c|c|c|c}
\hline Formulação & Cimento (g) & Areia (g) & Fíler calcário (g) & Aditivo (g) & a/c & Microfibra (g) \\
\hline REF & & & & & 1,34 & - \\
L05 & & & & & 1,70 & 0,035 \\
L03 & & & & & 1,55 & 0,021 \\
L01 & & & & 1,35 & 0,007 \\
M05 & \multirow{2}{*}{5,379} & 0,714 & & 1,70 & 0,035 \\
M03 & & & & & 1,55 & 0,021 \\
M01 & & & & 1,35 & 0,007 \\
C05 & & & & 1,70 & 0,035 \\
C03 & & & & & 1,35 & 0,021 \\
C01 & & & & & \\
\hline
\end{tabular}

\section{Métodos}

As argamassas desenvolvidas na pesquisa foram analisadas em seu estado fresco. Investigou-se a reologia das argamassas utilizando o método de ensaio de squeeze-flow NBR 15839 (ABNT, 2010). Nesse tipo de análise, a argamassa sofre uma compressão de carga, em velocidade constante de $0,1 \mathrm{~mm} / \mathrm{s}$, e o resultado se apresenta como um gráfico contendo a curva de tensão pela deformação. Dessa forma é possível verificar a trabalhabilidade da argamassa.

Também foram avaliados o teor de ar em argamassa fresca NBR 47 (ABNT, 2005) e a retenção de água NBR 13277 (ABNT, 1995). Para determinar o teor de ar foi utilizada uma norma de concreto no estado fresco para direcionar o desenvolvimento do ensaio; contudo, o recipiente utilizado no ensaio apresentou dimensões menores que o recipiente para concreto. Nesse ensaio, a argamassa é depositada no interior do recipiente cilíndrico e, por meio da mudança de volume devido à alteração de pressão, é possível detectar o teor de ar contido da argamassa no estado fresco. O ensaio de retenção de água determina a facilidade ou a dificuldade de a argamassa manter sua água de amassamento sem dispersá-la para o meio ambiente.

A viscosidade das argamassas desenvolvidas foi determinada por meio do Viscosímetro de Brookfield DV2, com spindle tipo $\mathrm{T}$ e velocidade $0,2 \mathrm{rpm}$. As argamassas desenvolvidas na pesquisa apresentaram viscosidade acima da capacidade de rotação máxima do viscosímetro, portanto foi necessário adicionar 2\% de água às misturas, com relação à água de amassamento. Com base nas NBR 13277 (ABNT, 1995) e NBR 13276 (ABNT, 2016b), foram determinadas a densidade e o índice de consistência das argamassas, respectivamente. Os resultados obtidos na pesquisa passaram por análise estatística de regressão linear, com índice de confiança de $95 \%$.

\section{Resultados e discussões}

Na Tabela 3 estão apresentados os resultados obtidos nesta pesquisa. A partir deles, foi possível analisar a influência da inserção de microfibras e os diferentes teores de adição nas propriedades das argamassas no estado fresco. 
Tabela 3 - Resultados obtidos nos ensaios no estado fresco

\begin{tabular}{c|c|c|c|c|c}
\hline Formulação & $\begin{array}{c}\text { Densidade } \\
\left(\mathbf{g} / \mathbf{c m}^{\mathbf{3}}\right)\end{array}$ & $\begin{array}{c}\text { Teor de ar } \\
(\mathbf{\%})\end{array}$ & $\begin{array}{c}\text { Retenção de água } \\
(\mathbf{\%})\end{array}$ & $\begin{array}{c}\text { Índice de } \\
\text { consistência }(\mathbf{m m})\end{array}$ & $\begin{array}{c}\text { Viscosidade } \\
(\mathbf{1 0}\end{array} \mathbf{\text { cP) }}$ \\
\hline REF & 1,89 & 7,50 & 86,50 & 237 & 499 \\
L05 & 1,89 & 8,90 & 88,70 & 209 & 626 \\
L03 & 1,89 & 8,00 & 88,40 & 226 & 593 \\
L01 & 1,91 & 7,90 & 87,90 & 243 & 538 \\
M05 & 1,88 & 8,00 & 87,90 & 220 & 584 \\
M03 & 1,88 & 7,90 & 87,10 & 225 & 557 \\
M01 & 1,90 & 7,70 & 81,10 & 241 & 547 \\
C05 & 1,87 & 10,00 & 90,10 & 242 & 535 \\
C03 & 1,88 & 9,00 & 89,90 & 244 & 526 \\
C01 & 1,88 & 8,50 & 89,23 & 251 & 519 \\
\hline
\end{tabular}

Primeiramente, observou-se que a inserção de microfibras promoveu a incorporação de ar na mistura (Figura 5). Isso pode ocorrer em razão de que a dispersão das microfibras na matriz cimentícia induz o aprisionamento de vazios no sistema. Além disso, o contato das partículas do composto com a superfície plana das microfibras provoca um efeito parede, gerando bolhas dentro do sistema. As argamassas com microfibra curta foram as que apresentaram maiores resultados de teor de ar. Esse tipo de microfibra apresenta maior densidade do que as demais, sendo assim, para os mesmos teores de adição em massa, têmse menor volume de microfibras na mistura. Portanto, sua dispersão é facilitada, promovendo a retenção do ar no compósito. Ademais, o efeito da microfibra sobre a incorporação de ar, por sua vez, resulta na redução da densidade das argamassas.

A adição de microfibras nas argamassas também apresentou maior capacidade de retenção de água. A partir dos resultados expostos na Tabela 3, é possível verificar que as argamassas que continham microfibras apresentaram um valor de retenção de água superior ao da argamassa de referência, que não teve adição de microfibras. As microfibras são constituídas por microtubos de celulose, o que permite a absorção de água da mistura por meio do mecanismo de pressão capilar. No entanto, a microfibra curta mostrou ter maior capacidade de retenção de água, pois seu diâmetro é menor que os das demais, o que intensifica a pressão de sucção do microtubo. Além disso, o efeito sobre a retenção de água também ocorre porque a microfibra curta é a que tem maior teor de celulose das três e, portanto, é a mais hidrofílica. Ou seja, a capacidade de retenção de água das argamassas está condicionada à dimensão das microfibras, à pressão capilar gerada por estas no compósito e pela composição química (quantidade de celulose), em concordância com as constatações de Coutts (1988), Alvarez, Ruscekaite e Vazquez (2003), Sales (2006) e Onuaguluchi e Banthia (2016), respectivamente.

Na Figura 6 são apresentados os resultados da avaliação da consistência com base nos dados de viscosidade e relação a/c.

A presença de microfibras aumentou a viscosidade das argamassas em relação à referência, atribuindo-se a isso três hipóteses. Em primeiro lugar, o aumento da quantidade de partículas sólidas reduz a capacidade de escoamento da mistura. Em segundo lugar, por sua característica hidrofílica, a microfibra de celulose absorve parte da água de amassamento aumentando seu volume, ou seja, ocupando mais espaço dentro do compósito. Sendo assim, quanto maior for a microfibra, maior será sua alteração volumétrica e, consequentemente, maior será também sua viscosidade. Em terceiro e último lugar, o comprimento das microfibras aumenta a susceptibilidade ao entrelaçamento, o que também contribui com o aumento da viscosidade. Todos esses efeitos puderam ser verificados nos resultados de viscosidade, nos quais as argamassas com microfibra longa e altos teores de adição apresentaram os maiores valores.

Analisando os resultados de consistência, verificou-se que, mesmo a relação a/c tendo sido alterada na mesma proporção de adição das microfibras, para os diferentes tipos os comportamentos foram distintos. Isso porque na dosagem de água não foram consideradas suas características, como densidade, comprimento e diâmetro. Por exemplo, todas as formulações com microfibras curtas e as formulações L01 e M01 apresentaram maior fluidez, pois essas mesmas misturas incorporaram maior quantidade de ar. As bolhas de ar, por sua vez, atuam lubrificando os grãos eliminando parte do atrito entre eles e promovendo a fluidez das argamassas (SILVA, 2006). Por outro lado, as demais formulações reduziram o índice de consistência em até $11,80 \%$. Posto isso, verificou-se que a consistência está condicionada ao entrelaçamento entre as

184 Pescarolo, A.; Silva, S. H. L. da.; Pinto, M. C. C.; Costa, M. do R. de M. M. da 
microfibras, que é recorrente para as fibras mais longas e para os maiores teores de adição, resultando na redução da fluidez.

Por fim, os resultados obtidos de densidade, retenção de água, consistência e viscosidade foram analisados estatisticamente por meio de regressão linear múltipla (RLM). Cada um desses resultados foi selecionado como variável dependente e correlacionado com as variáveis independentes de cada formulação, sendo elas: teor de adição, teor de celulose, comprimento, e diâmetro das microfibras; a/c. Na Tabela 4 são apresentados os resultados da análise RLM considerando as 10 formulações com três amostras por ensaio, o que totalizou 30 observações. O R múltiplo traduz a correlação entre a variável dependente e as independentes, sendo que quanto mais próximo de 1, maior é a correlação. Além disso, o quadrado de R representa o quanto a equação de RLM se ajusta aos dados analisados. Sendo assim, constatou-se que as variáveis analisadas influenciaram consideravelmente no desempenho das argamassas quanto à densidade, retenção de água e consistência, tendo obtido resultados de $\mathrm{R}$ múltiplo maior que $85 \%$ e quadrado de $\mathrm{R}$ maior de $72 \%$. Porém, para a viscosidade isso não foi observado uma vez que o R múltiplo foi de $62 \%$ tendo um quadrado de $\mathrm{R}$ de $39 \%$, o que demonstra que apenas as variáveis analisadas não são suficientes para alterar a viscosidade das argamassas.

Os resultados do ensaio de Squeeze-flow das argamassas com fibras longas, médias e curtas estão apresentados, respectivamente, nas Figuras 7, 8 e 9.

Figura 5 - Densidade e teor de ar incorporado

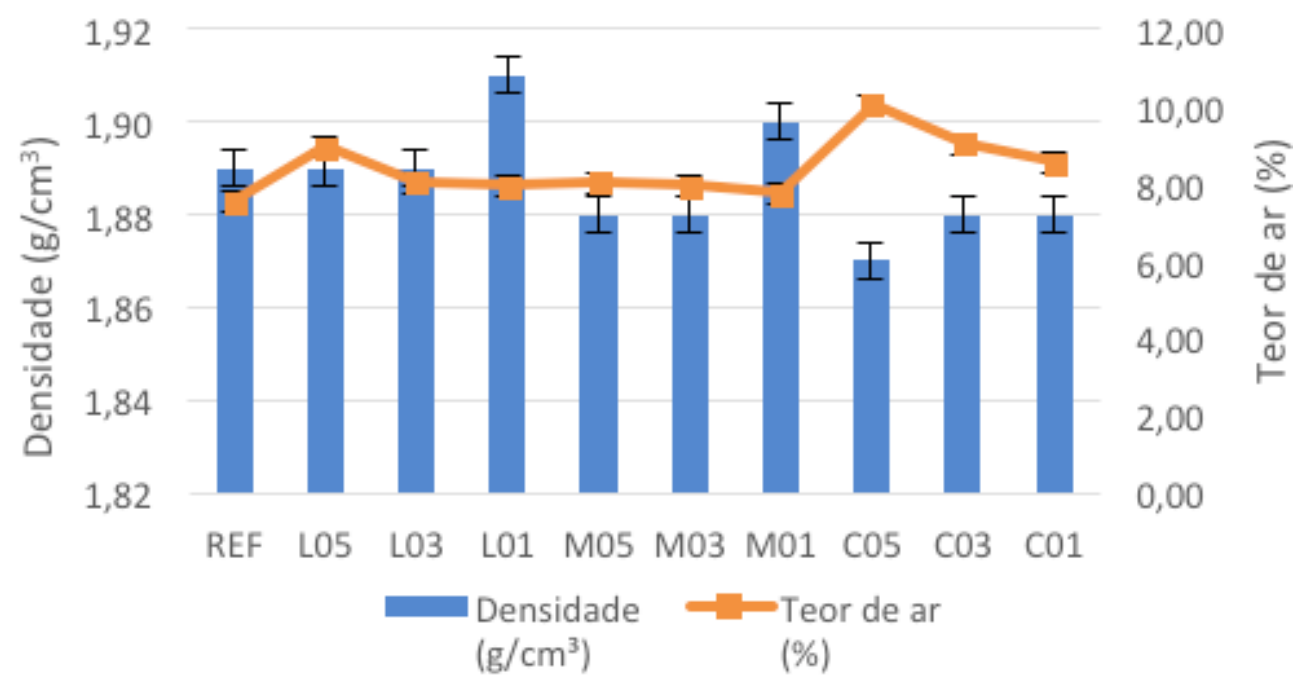

Figura 6 - Resultados de viscosidade, índice de consistência e relação a/c

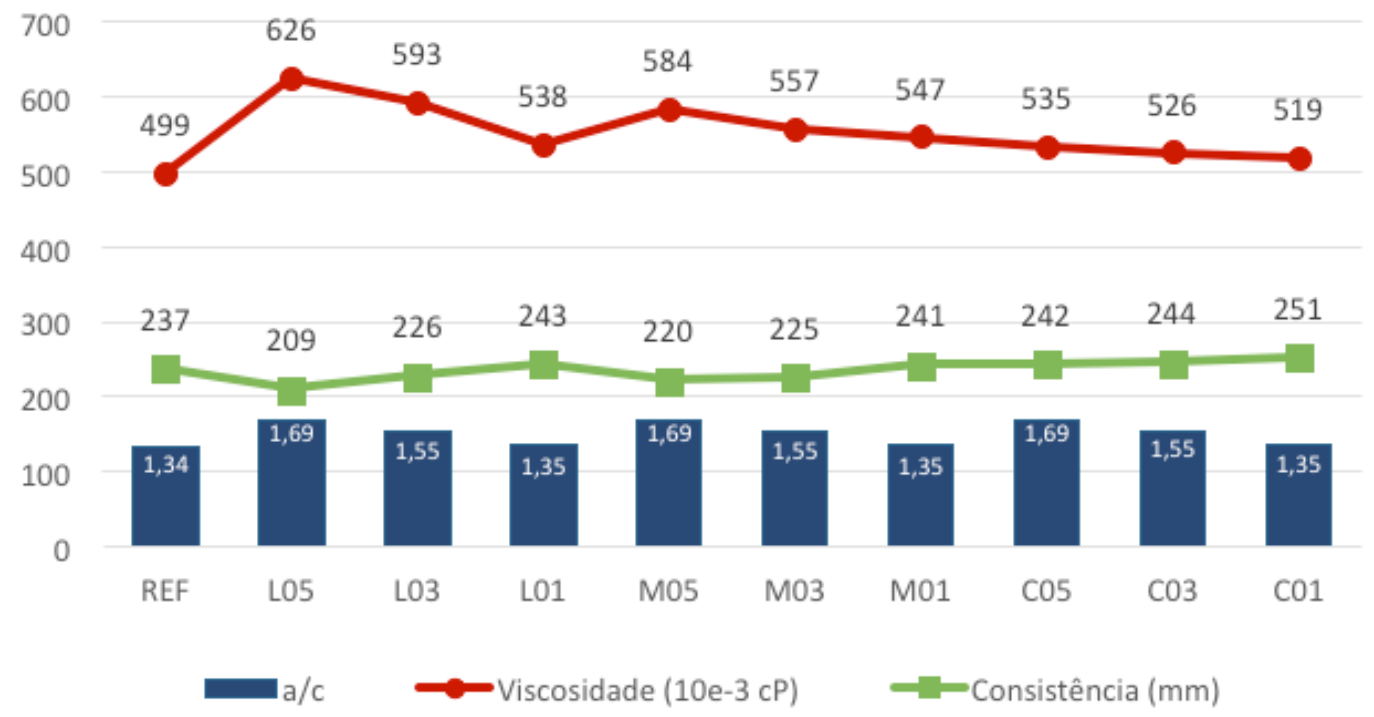


Tabela 4 - Resultados da análise de regressão linear múltipla

\begin{tabular}{c|c|c|c}
\hline $\begin{array}{c}\text { Características da } \\
\text { microfibra }\end{array}$ & R múltiplo & Quadrado de R & $\begin{array}{c}\text { Quantidade de } \\
\text { observações }\end{array}$ \\
\hline Densidade & 0,85 & 0,72 & \\
Retenção de água & 0,87 & 0,75 & 30 \\
Consistência & 0,94 & 0,89 & \\
Viscosidade & 0,62 & 0,39 & \\
\hline
\end{tabular}

Figura 7 - Resultados do ensaio de Squeeze-flow para as formulações com microfibra longa

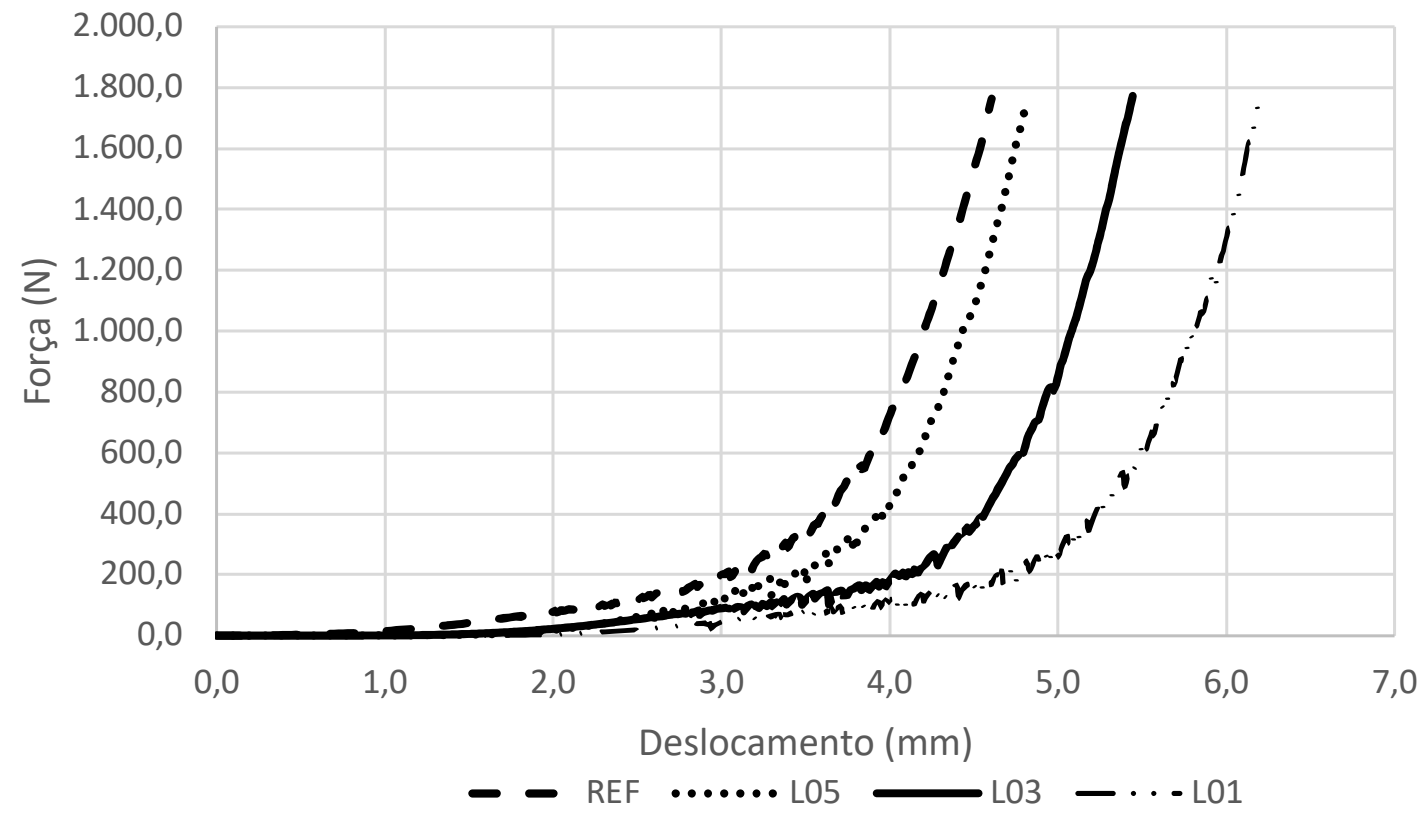

Figura 8 - Resultados do ensaio de Squeeze-flow para as formulações com microfibra média

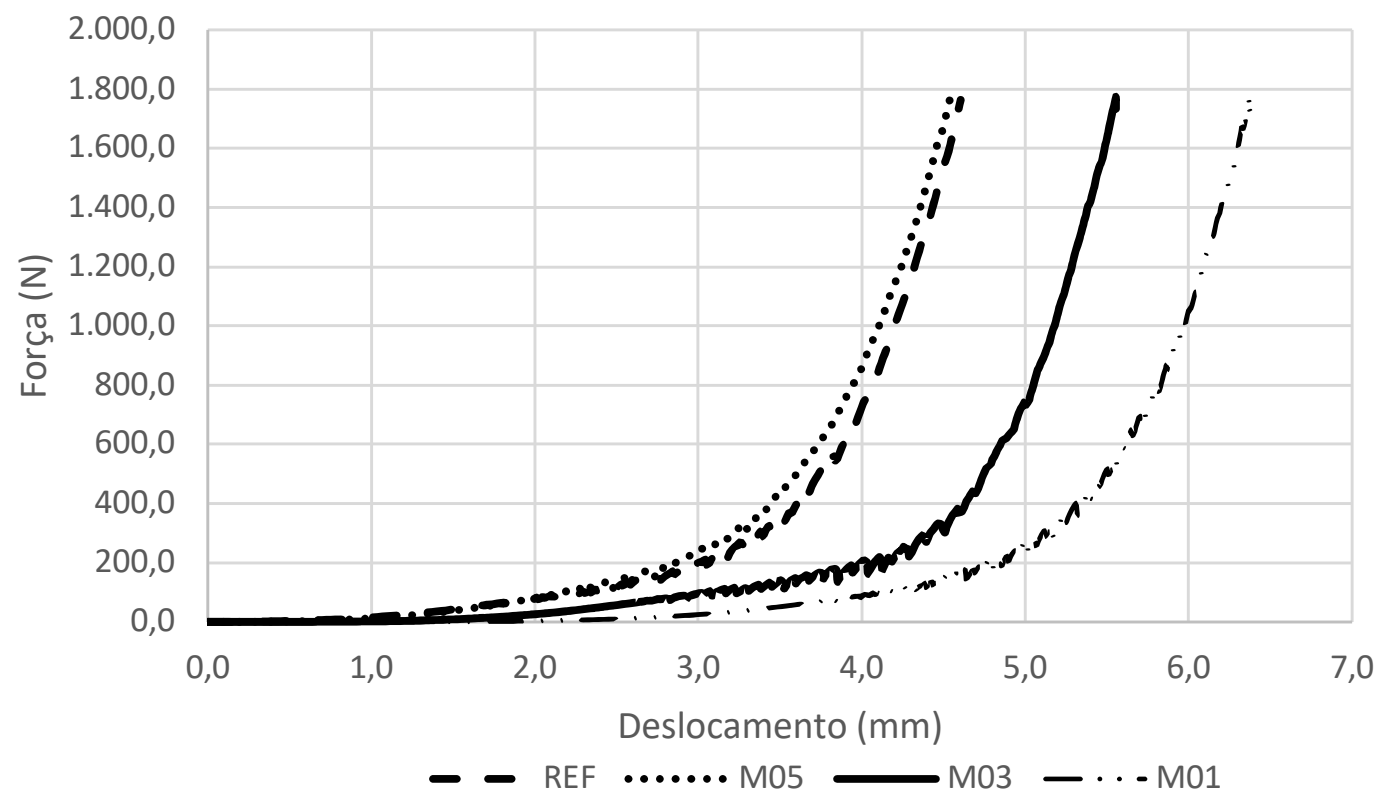


Figura 9 - Resultados do ensaio de Squeeze-flow para as formulações com microfibra curta

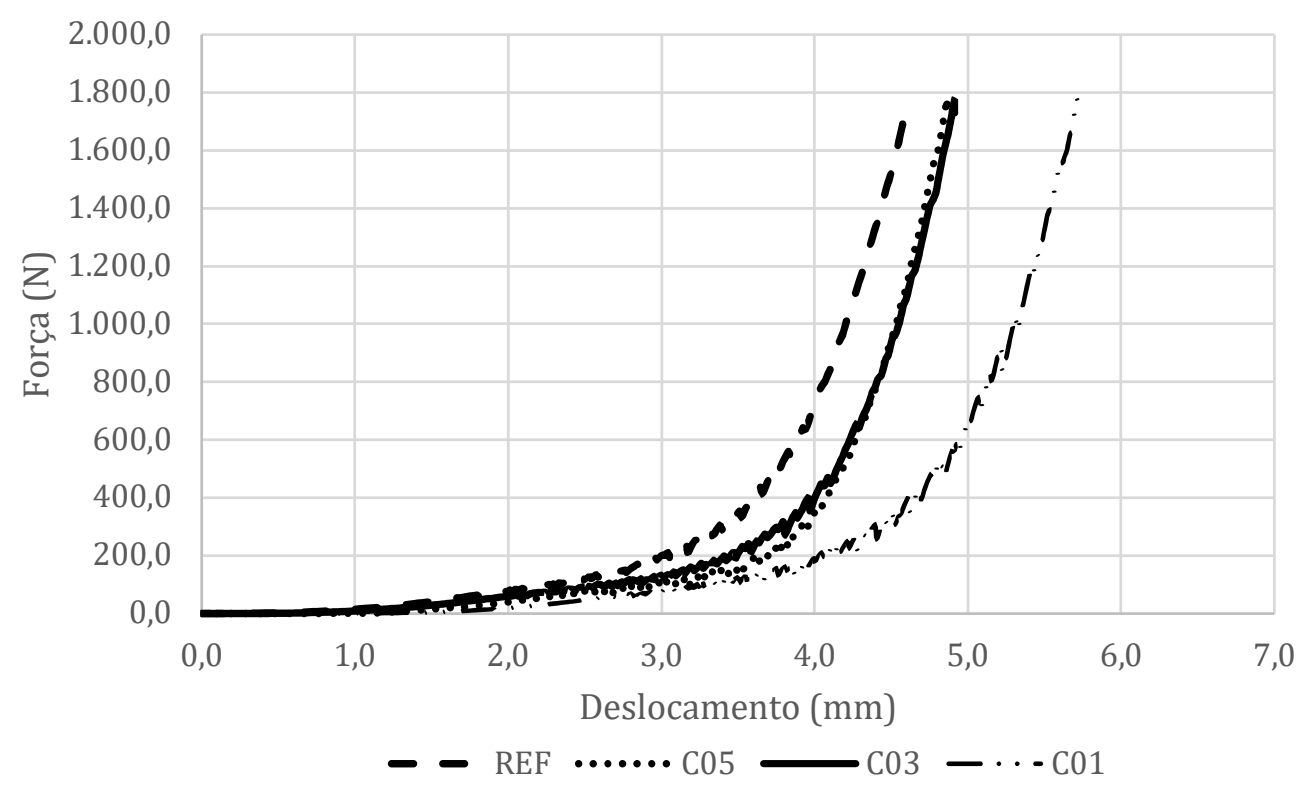

Em todos os gráficos, percebe-se que a argamassa de referência apresentou o menor deslocamento, o que a caracteriza como a argamassa menos plástica. Em contrapartida, as formulações contendo microfibras apresentaram maior deformabilidade. Knapen e Van Gemert (2009) avaliaram a inserção de polímeros solúveis em água em argamassas e constataram que esses materiais, por meio do efeito de lubrificação e incorporação de ar na matriz, aumentam a trabalhabilidade. Sendo as microfibras compostas por celulose, que é um polímero natural, pode-se esperar que elas também se comportem como os demais polímeros em algumas características. Portanto, bem como os polímeros solúveis em água, possivelmente as microfibras empregadas nesta pesquisa atuaram como lubrificantes nas misturas, promovendo a deformação e reduzindo a tensão de escoamento. Pressupõe-se que as microfibras afastem as partículas sólidas reduzindo o atrito entre elas, logo retardando a fase de imbricação.

Observa-se pelos gráficos que todos os teores de microfibra promoveram o deslocamento das argamassas, ressaltando que o teor de $0,1 \%$ foi o que mais impactou o fluxo. Decerto, o teor ótimo de microfibra está mais próximo do teor de $0,1 \%$ que dos demais teores. Em contrapartida, o aumento dos teores para $0,3 \%$ e $0,5 \%$ restringiram o deslocamento das argamassas, apresentando menor deslocamento nos gráficos de Squeeze-flow. Isso possivelmente ocorreu em função de esses teores terem ultrapassado o teor ótimo de microfibra. Ao ser ultrapassado o teor ótimo, provavelmente ocorreu uma má dispersão e, consequentemente, o entrelaçamento das microfibras. Sendo assim, o excesso de microfibra tende a restringir o fluxo da argamassa, observando-se pelos gráficos que o deslocamento dos teores de $0,3 \%$ e $0,5 \%$ ficaram próximos do deslocamento da argamassa de referência.

Avaliando o comportamento reológico das argamassas frente às dimensões das microfibras, identifica-se que o efeito de lubrificação é mais expressivo para as microfibras mais longas, pois estas ocupam maior espaço no composto, afastando ainda mais sólidos. Isto posto, verifica-se que as formulações com as microfibras longa e média são mais plásticas do que aquelas com microfibra curta, em concordância com as constatações de Banfill et al. (2006). Além disso, a microfibra curta, em virtude de seu teor de celulose, retém maior quantidade da água de amassamento, limitando também a deformação das formulações. Ressalta-se que, para todas as formulações com microfibra, o aumento do teor de adição resultou na sobreposição do efeito de afastamento pelo excesso de matéria, gerando entrelaçamento e reduzindo a plasticidade pelo aumento do consumo da água de amassamento.

\section{Considerações finais}

A análise dos resultados apresentados mostra que a adição de microfibras de celulose nas argamassas de revestimento acaba por influenciar suas características e seu desempenho. A inserção de microfibras promoveu a incorporação de ar devido a sua dispersão e ao efeito parede recorrente do atrito entre elas as 
partículas da mistura. A retenção de água das argamassas também foi favorecida com a presença das microfibras, uma vez que estas são constituídas de microtubos de celulose e têm característica hidrofílica.

Em todas as argamassas com adição houve o aumento da viscosidade, pois nestas havia um maior volume de partículas sólidas e - principalmente nas maiores concentrações e dimensões - as microfibras tenderam ao entrelaçamento. Em contrapartida, o índice de consistência foi maior para as formulações L01, M01 e com microfibras curtas, porque estas apresentaram maior teor de ar, favorecendo a fluidez por meio do mecanismo de lubrificação dos grãos. A análise de regressão linear mostrou que as características físicas e químicas das microfibras bem como seus teores de adição exercem influência considerável sobre os resultados de densidade, teor de ar incorporado, retenção de água, consistência e viscosidade.

A presença das adições alterou a reologia das argamassas conforme observado nos resultados do Squeezeflow. As microfibras médias e longas promoveram a deformabilidade dos materiais em virtude do efeito de lubrificação das misturas a partir do afastamento das partículas sólidas, resultando no retardamento da fase de imbricamento.

Ressalta-se que os resultados obtidos permitiram identificar a influência das microfibras no desempenho das argamassas no estado fresco. Todavia, a definição do teor ótimo e do tipo de adição adequada estão sujeitos às aplicações das diferentes argamassas.

\section{Referências}

ALVAREZ, V. A.; RUSCEKAITE, R. A.; VAZQUEZ, A. Mechanical Properties water absorption behavior of composites made from a biodegradable matrix and alkaline-treated sisal fibers. Journal of Composites Materials, v. 37, n. 17, p. 1575-1588, 2003.

ARDANUY, M.; CLARAMUNT, J.; TOLEDO FILHO, R. D. Cellulosic fiber reinforced cement-based composites: a review of recent research. Construction and Building Materials, v. 79, p. 115-128, 2015.

ASSOCIAÇÃO BRASILEIRA DE NORMAS TÉCNICAS. NBR NM 248: agregados: determinação da composição granulométrica. Rio de Janeiro, 2003.

ASSOCIAÇÃO BRASILEIRA DE NORMAS TÉCNICAS. NBR 13276: argamassa de revestimento e assentamento de paredes e tetos: determinação do índice de consistência. Rio de Janeiro, $2016 \mathrm{~b}$.

ASSOCIAÇÃO BRASILEIRA DE NORMAS TÉCNICAS. NBR 13277: argamassa para assentamento e revestimento de paredes e tetos: determinação da retenção de água. Rio de Janeiro, 1995.

ASSOCIAÇÃO BRASILEIRA DE NORMAS TÉCNICAS. NBR 15839: argamassa de revestimento e assentamento de paredes e tetos: caracterização reológica pelo método do Squeeze Flow. Rio de Janeiro, 2010 .

ASSOCIAÇÃO BRASILEIRA DE NORMAS TÉCNICAS. NBR 16541: argamassa para assentamento e revestimento de paredes e tetos: preparo da mistura para a realização de ensaios. Rio de Janeiro, 2016 a.

ASSOCIAÇÃO BRASILEIRA DE NORMAS TÉCNICAS. NM 47: argamassa de revestimento e assentamento de paredes e tetos e paredes: determinação da densidade de massa e teor de ar incorporado. Rio de Janeiro, 2005.

BANFILL, P. F. G. et al. Rheology of low carbon fibre content reinforced cement mortar. Cement and Concrete Composites, v. 28, n. 9, p. 773-780, 2006.

COUTTS, R. S. P. Wood fibre reinforced cement composites. In: SWAMY, R. N. (ed.). Natural fibre reinforced cement and concrete. Glasgow: Blackie, 1988.

FARUK, O. et al. Biocomposites reinforced with natural fibers: 2000-2010. Progress in polymer science, v. 37, n. 11, p. 1552-1596, 2012.

GURGEL, L. V. A. Mercerização e modificação química de celulose e bagaço de cana-de-açucar com anidrido succínico e trietilenotetramina: preparação de novo materiais quelantes para a adsorção de $\mathrm{Pb}$ (II), Cd (II), Cr (VI) e Cu (II). Ouro Preto, 2007. Dissertação (Mestrado em Engeharia Ambiental) Universidade Federal de Ouro Preto, Ouro Preto, 2007.

JAWAID, M.; KHALIL, H. P. S. A. Cellulosic/synthetic fibre reinforced polymer hybrid composites: a review. Carbohydrate Polymers, v. 86, p. 1-18, 2011.

J. RETTENMAIER \& SÖHNE. Welcome to the world of fibers. Berlim, 2012.

188 Pescarolo, A.; Silva, S. H. L. da.; Pinto, M. C. C.; Costa, M. do R. de M. M. da 
KNAPEN, E.; VAN GEMERT, D. Cement hydration and microstructure formation in the presence of watersoluble polymers. Cement and concrete Research, v. 39, n. 1, p. 6-13, 2009.

MENDES, F. M. et al. Topochemical characterization of sugar cane pretreated with alkaline sulfite. Industrial Crops and Products, v. 69, p. 60-67, 2015.

MOTTA, M. S.; SOUZA, L. M. S.; SILVA, F. A. Early-age shrinkage of cement pastes with polypropylene and curaua fibres. Advances in Cement Research, v. 33, n. 4, p. 156-167, 2021.

NARAGANTI, S. R.; PANNEM, R. M. R.; PUTTA, J. Impact resistance of hybrid fibre reinforced concrete containing sisal fibres. Ain Shams Engineering Journal, v. 10, n. 2, p. 297-305, 2019.

ONUAGULUCHI, O.; BANTHIA, N. Plant-based natural fibre reinforced cement composites: a review. Cement and Concrete Composites, v. 68, p. 96-108, 2016.

PERUZZI, A, P. Comportamento das fibras de vidro convencionais em matriz de cimento Portland Modificada com látex e adição de sílica ativa. São Carlos, 2002. Dissertação (Mestrado em Arquitetura) Escola de São Carlos, São Carlos, 2002.

SALES, A. T. C. Retração, fluência e fraturas em compósitos cimentícios reforçados com polpa de bambu. Rio de Janeiro, 2006. Tese (Doutorado em Engenharia Civil) - Programa de Pós-Graduação em Engenharia Civil, Pontifícia Universidade Católica, Rio de Janeiro, 2006.

SANTOS, S. F.; TEIXEIRA, R. S.; SAVASTANO JUNIOR, H. Interfacial transition zone between lignocellulosic fiber and matrix in cement-based composites. London: Woodhead Publishing, 2017.

SAVASTANO JUNIOR, H. Materiais à base de cimento reforçados com fibra vegetal: reciclagem de resíduos para construção de baixo custo. São Paulo, 2000. Tese (Doutorado em Engenharia Civil) - Escola Politécnica, Universidade de São Paulo, São Paulo, 2000.

SILVA, R. P. Argamassas com adição de fibras de polipropileno: estudo do comportamento reológico. São Paulo, 2006. 191 f. Dissertação (Mestrado em Engenharia) - Escola Politécnica, Universidade de São Paulo, São Paulo, 2006.

SIQUEIRA, J. E. L. Utilização de fibras naturais e sintéticas em argamassas de revestimento de alvenaria: estudo comparativo de desempenho. Florianópolis, 2006. Dissertação (Mestrado em Engenharia Civil) - Universidade Federal de Santa Catarina, Florianópolis, 2006.

WEI, J.; MEYER, C. Degradation mechanisms of natural fiber in the matrix of cement composites. Cement and Concrete Research, v. 73, p. 1-16, 2015.

\section{Agradecimentos}

À Coordenação de Aperfeiçoamento de Pessoal de Nível Superior (CAPES), ao Programa de Pós-Graduação em Engenharia de Construção Civil PPGECC e ao Laboratório de Tecnologia de Argamassas do Departamento de Construção Civil (LATECA/DCC) da Universidade Federal do Paraná (UFPR) e à empresa produtora das fibras pelo financiamento desta pesquisa. 


\section{Aline Pescarolo}

Programa de Pós-Graduação em Engenharia da Construcão Civil | Universidade Federal do Paraná | Rua Evaristo F. Ferreira da Costa, 369377, Jardim das Américas | Curitiba - PR - Brasil | CEP 82590-300 | Tel.: (41) 3361-3110 | E-mail: alinepesca@hotmail.com

\section{Sarah Honorato Lopes da Silva}

Coordenação de Engenharia Civil | Universidade Tecnológica Federal do Paraná | Rua Marcílio Dias, 635, Jardim Paraiso | Apucarana - PR - Brasol | CEP 86812-460 | Tel.: (43) 3162-1200 | E-mail: sarahhlds@gmail.com

\section{Maria Clara Cavalini Pinto}

Programa de Pós-Graduação em Engenharia da Construção Civil | Universidade Federal do Paraná | E-mail: mclaracavalini@gmail.com

Marienne do Roio de Mello Maron da Costa

Programa de Pós-Graduação em Engenharia da Construção Civil | Universidade Federal do Paraná | E-mail: mariennemaron@gmail.com

\section{Ambiente Construído}

Revista da Associação Nacional de Tecnologia do Ambiente Construído

Av. Osvaldo Aranha, $99-3^{\circ}$ andar, Centro

Porto Alegre - RS - Brasil

CEP $90035-190$

Telefone: +55 (51) 3308-4084

www.seer.ufrgs.br/ambienteconstruido www.scielo.br/ac

E-mail: ambienteconstruido@ufrgs.br

This is an open-access article distributed under the terms of the Creative Commons Attribution License.

190 Pescarolo, A.; Silva, S. H. L. da.; Pinto, M. C. C.; Costa, M. do R. de M. M. da 